\title{
DOENÇAS INFECCIOSAS NO CONTEXTO DAS MUDANÇAS CLIMÁTICAS E DA VULNERABILIDADE SOCIOAMBIENTAL
}

\author{
ZEZZO, Larissa Vieira - larisvz@gmail.com \\ Universidade Estadual de Campinas / UNICAMP \\ COLTRI, Priscila Pereira - pcoltri@cpa.unicamp.br \\ Universidade Estadual de Campinas / UNICAMP \\ MIRANDA, Marina Jorge de - marinajmiranda@gmail.com \\ Ministerio da Saúde / MS \\ ZULLO JÚNIOR, Jurandir - jurandir@cpa.unicamp.br \\ Universidade Estadual de Campinas / UNICAMP
}

Submetido em: $29 / 07 / 2020$

Aceito para publicação em: 24/05/2021

Publicado em: 08/06/2021

DOI: http://dx.doi.org/10.5380/abclima.v28i0.75500

\begin{abstract}
RESUMO: Os estudos associando às mudanças climáticas e a saúde foram definidos como um campo de pesquisa oficial e de atuação nos anos 90 , e, desde então, eles vêm aumentando significativamente, assim como a consciência sobre a influência da variabilidade climática e dos eventos extremos no surgimento de doenças infecciosas. Com isso, este estudo teve o objetivo de demonstrar a relação entre as doenças infecciosas relatadas pela Organização Mundial da Saúde (OMS), epidêmicas e pandêmicas, com as alterações climáticas e ambientais, destacando ainda a questão da vulnerabilidade socioambiental. Para tanto, foi utilizada uma revisão integrativa da literatura, contemplando estudos acadêmicos, como teses e artigos publicados entre os anos de 1991 a 2021, além de documentos nacionais e internacionais. Ao todo, revisouse um conjunto de amostra de 81 trabalhos $(n=81)$ e os resultados destacaram um padrão quanto ao surgimento e ao reaparecimento de doenças infecciosas que indicam o vínculo delas com a pressão das mudanças climáticas e ambientais sobre o meio, especialmente em regiões mais vulneráveis da Ásia e da África. Sugeriu-se, nesse contexto, a adoção de medidas de adaptação ao clima para diminuir a pressão sobre os recursos naturais, atenuar os riscos ambientais e, consequentemente, os impactos econômicos, sociais e de saúde. Dessa forma, esse trabalho contribui ao campo de pesquisa de saúde e mudanças climáticas, ao pontuar os fatores ambientais, climáticos e, até mesmo, sociais, relacionados ao surgimento de algumas das doenças que foram, ou são, epidêmicas ou pandêmicas, e, a partir dos quais, é possível desenvolver medidas de mitigação e adaptação a serem implementadas em contexto local, especialmente nas regiões mais vulneráveis.
\end{abstract}

PALAVRAS-ChAVe: Variabilidade Climática; Perda de Biodiversidade; Doenças Infecciosas; Vulnerabilidade

\section{INFECTIOUS DISEASES IN THE CONTEXT OF CLIMATE CHANGE AND SOCIO- ENVIRONMENTAL VULNERABILITY}

ABSTRACT: Surveys associating climate change and health were defined as a research field and action in the 1990 s and since then, studies about this relationship have increased, as has awareness over the influence of climate variability and extreme events on the emergence of infectious diseases. Hence, this study aimed to demonstrate the relationship between infectious diseases reported by the World Health Organization (WHO), epidemic and pandemic, with climate and environmental changes, highlighting the issue of socio-environmental vulnerability. Given the objective, an integrative literature review was used, including academic studies, such as theses and articles 
published between 1991 and 2021, as well as to national and international documents. Altogether, a sample set of 81 studies was reviewed $(n=81)$ and the results highlighted a pattern regarding the emergence and reappearance of infectious diseases that indicate their link with the pressure of climate and environmental changes on the environment, especially in the most vulnerable regions of Asia and Africa. In this context, the adoption of climate adaptation measures was suggested to reduce the pressure on natural resources, mitigate environmental risks and, consequently, social, economic and health impacts. Thus, this work contributed to the field of health research and climate change, by point out the environmental, climatic and even social factors, related to the emergence of some of the diseases that were, or are, epidemic or pandemic, and from which, it is possible to develop measures of mitigation and adaptation to be implemented in the local context, especially in regions that are more vulnerable.

KEYWORDS: Climate Variability; Loss of Biodiversity; Infection Disease; Vulnerability

\section{INTRODUÇÃO}

Desde o início dos anos 90, os estudos sobre mudanças climáticas e saúde foram definidos formalmente como um campo de pesquisa e atuação, tendo um maior número de publicações a partir dos anos 2000. "Os relatórios do Intergovernmental Panel on Climate Change (IPCC) de 1995, 2001, 2007 e 2014, indicaram, em suas conclusões, um progresso na compreensão dos efeitos e riscos das mudanças climáticas no âmbito da saúde" (EBI e HESS, 2017).

Estes mesmos autores comentam que o conhecimento base sobre 0 assunto ainda é muito escasso, diferentemente do que ocorre em outros setores, como da agricultura e climatologia, em razão do pouco investimento feito em pesquisas sobre saúde e mudanças climáticas.

Cabe ressaltar que o IPCC foi fundado pela Organização Meteorológica Mundial (OMM) juntamente com o programa das Nações Unidas para o Meio Ambiente, na década de 80 , a partir de uma série de evidências ambientais sobre o impacto dos gases de efeito estufa sobre o clima. "Dessa forma, o IPCC tem o objetivo de fornecer conhecimentos científicos sobre mudanças climáticas, suas potenciais consequências para as pessoas e os sistemas naturais, bem como medidas de mitigação e adaptação para preparar e gerenciar riscos ambientais, sociais e até mesmo econômicos decorrentes das alterações climáticas" (EBI e HESS, 2017).

O primeiro relatório do IPCC abordando questões de saúde foi redigido em 1995 e levantou pontos importantes, como o fato das mudanças climáticas terem múltiplos riscos ainda não reconhecidos à saúde humana, dos efeitos diretos e indiretos do clima na saúde, a relação dos padrões de variabilidade climática com os riscos diferenciados às populações mais vulneráveis, e outros mais específicos, como doenças e mortes associadas à eventos extremos e o aumento na prevalência de doenças infecciosas em razão da sazonalidade ou dinâmica da transmissão, tendo a malária como exemplo (EBI e HESS, 2017).

No ano de 2007, o 40 relatório do IPCC destacou conclusões sobre os aspectos das mudanças climáticas na saúde, mencionando a vulnerabilidade de países de baixa renda, alterações no comportamento de vetores e o surgimento de doenças (UCHOA et al., 2019).

Desde os anos 2000, artigos científicos vêm alertando sobre a relação entre as doenças infecciosas e as alterações nos padrões climáticos, demonstrando, a partir de modelos matemáticos e estudos teóricos, que 
eventos de diferentes magnitudes, tanto os extremos climáticos, como as pequenas mudanças nas variáveis meteorológicas, podem mudar 0 comportamento das doenças e propiciar o surgimento de novas (LIANG et al., 2016; YI et al., 2019; SMITH, 2019; METCALF et al., 2017; ALI et al., 2016).

Nesse contexto, EBI e HESS (2017) ainda pontuam que avaliar questões de vulnerabilidade, adaptação e capacidade pode informar melhor a sociedade sobre quais as lacunas nesse tipo de pesquisa, permitindo um melhor gerenciamento e gestão de riscos à saúde, no que se refere a políticas e tomadas de decisões.

Diante do exposto, este trabalho objetivou demonstrar, por meio de uma revisão integrativa de literatura, a relação entre as doenças infecciosas relatadas pela Organização Mundial da Saúde (OMS), como epidêmicas ou pandêmicas, com as alterações climáticas e ambientais.

Objetivou-se, também, evidenciar questões vinculadas à vulnerabilidade socioambiental, visto que as projeções globais demostram que as alterações climáticas favorecem 0 surgimento de novas doenças, bem como 0 reaparecimento de outras, que podem levar a problemas de saúde pública e econômica para diversos países.

Destaca-se que, esse artigo, não tem como objetivo fornecer uma análise e visão generalizada sobre a relação das doenças infecciosas com as mudanças climáticas, mas sim, evidenciar em detalhes os mecanismos associados a cada uma das doenças descritas ao longo do trabalho e a relação particular dessas com as alterações climáticas e ambientais.

\section{METODOLOGIA}

A presente pesquisa foi realizada a partir de uma revisão integrativa de literatura, a qual possibilitou uma abordagem bastante vasta, ao utilizar dados da literatura teórica e empírica (Souza et al., 2010).

A revisão integrativa realizada no estudo, considerou um período de abrangência de 30 anos na busca por documentos acadêmicos, como teses e artigos publicados de 1991 a 2021, propiciando um olhar sobre a evolução do estado da arte sobre o tema em estudo e seus desdobramentos.

A obtenção dos documentos mencionados se deu a partir da base de dados da Scielo e Periódicos Capes, através do banco de teses da CAPES, de programas de pós-graduação de universidades brasileiras, assim como de revistas indexadas pela Elsevier, permitindo um levantamento de pesquisas nacionais e internacionais.

A busca nas bases de dados citadas ocorreu a partir da seleção de palavras-chave, de modo conjunto ou separado, tais como: "mudanças climáticas", "doenças infecciosas", "vulnerabilidade socioambiental", além disso, esses mesmos termos foram procurados também na língua inglesa.

Por meio da revisão integrativa, foi possível responder questões específicas relacionadas ao objetivo da pesquisa, como: Qual a influência das mudanças climáticas e ambientais no surgimento ou reaparecimento de doenças infecciosas? Qual a origem, características e questões ambientais relacionadas às doenças infecciosas relatadas pela Organização Mundial da Saúde (OMS)? 
Como a vulnerabilidade socioambiental está relacionada às doenças infecciosas no Brasil e no mundo?

Dessa forma, essas três questões norteadoras foram utilizadas como critério para seleção ou exclusão dos documentos encontrados durante o levantamento bibliográfico. Assim, por meio de uma leitura cuidadosa de cada documento, foi possível selecionar aqueles que responderam, ainda que parcialmente, ao menos uma das perguntas propostas acima, fato este que facilitou o desenvolvimento lógico do presente estudo e por conseguinte, sua elaboração.

Após a seleção inicial dos artigos, para responder os objetivos e perguntas do trabalho, segundo os critérios descritos, foram identificados ao todo 200 artigos e teses pertinentes ao tema em estudo, dos quais, após avaliação detalhada, foram selecionados 81 . Por fim, revisou-se um conjunto de amostra de 81 trabalhos $(n=81)$. Salienta-se que alguns dos materiais selecionados contemplaram o tema de forma mais ampla enquanto que outros se restringiram a uma das doenças infecciosas mencionadas, mas ainda respondendo a uma das questões norteadoras.

\section{RESULTADOS E DISCUSSÕES}

A partir dos documentos selecionados, foi possível contemplar o objetivo dessa pesquisa e discutir as questões apresentadas na metodologia, elaborando ainda, um quadro (Quadro 1) que exemplificasse a relação existente entre as doenças infecciosas e as mudanças ambientais e climáticas, tendo em vista que este último termo é definido como "uma mudança contínua e de longo prazo nas condições meteorológicas média, com efeito nas temperaturas da superfície, nas condições climáticas extremas, nas questões de secas e inundações, quanto ao aumento do nível do mar, bem como na ocorrência e frequência de fenômenos climáticos" (HASEN e SATO, 2016).

\subsection{A INFLUÊNCIA DAS MUDANÇAS CLIMÁTICAS E AMBIENTAIS SOBRE AS DOENÇAS INFECCIOSAS}

Para Patz et al. (2003), três grandes transições na relação entre humanos e microrganismos são reconhecidas, sendo elas: (1) as primeiras aglomerações humanas, que permitiram a introdução de agentes infecciosos no Homo sapiens; (2) posteriormente, as civilizações euroasiáticas, que através do contato militar e comercial, há 2000 anos atrás, trocaram doenças infecciosas entre si; e, por fim, (3) a expansão europeia nos últimos cinco séculos, que espalharam, por viagens transoceânicas, doenças infecciosas letais.

Este mesmo autor salienta que a dispersão e o aumento de doenças infecciosas refletem impactos demográficos, ambientais, tecnológicos e outras rápidas alterações na ecologia humana. Nesse contexto, as mudanças climáticas se destacam pela ampla gama de impactos que podem provocar quanto a ocorrência de doenças nas populações humanas, representando, dessa forma, uma quarta grande transição na relação anteriormente mencionada.

Os agentes infecciosos (como protozoários, bactérias e vírus) e os organismos que atuam como vetores (mosquitos e carrapatos, por exemplo) são 
muito pequenos e desprovidos de mecanismos termostáticos (GOULET, 2010; PATZ et al., 2003). Dessa forma, sua temperatura e o nível de fluidos são diretamente determinados pelo clima local. Assim, há uma faixa de condições climáticas limitadas para esses organismos, onde cada um deles, agentes infecciosos ou vetores, podem sobreviver e se reproduzir (PATZ et al., 2003).

Dentre as susceptibilidades climáticas que podem interferir no desenvolvimento de agentes infecciosos e vetores, pode-se citar a temperatura, o nível de precipitação, a elevação do nível dos oceanos, a circulação atmosférica e a duração da luz do sol (PATZ et al., 2003; METCALF et al., 2017; YI et al.; 2019). Os fatores mencionados acima podem, ainda, modificar a distribuição geográfica dos patógenos e dos vetores, potencializando o risco climático em outras comunidades (GORRIS, 2019).

Os efeitos das alterações no clima são sentidos, direta e indiretamente, com relação aos eventos extremos, ondas de calor, inundações e secas, bem como variações na qualidade da água, ar e alimentos (EBI et al, 2018; BALBUS et al., 2016; SMITH et al., 2014).

Nesse contexto, é importante considerar que as variações climáticas podem influenciar no surgimento ou reaparecimento de doenças infecciosas, uma vez que as condições ambientais definem a variedade de espécies de uma região, e, dessa forma, controlam a extensão espacial das doenças (GORRIS, 2019).

Os processos biológicos, como aqueles que envolvem o clico de vida de organismos patógenos e vetores de doenças, são diretamente induzidos pelos fatores climáticos (METCALF et al., 2017; CONFALONIERI et al., 2015).

Alguns estudos na área de ecologia avaliam os riscos da variabilidade climática sobre a transmissão de doenças infecciosas (WU et al., 2017; XIANG et al., 2017). No trabalho de Yi et al. (2019), os autores destacam algumas relações, assim como o aumento dos casos de malária na China, em razão de modificações nas características climáticas, que podem mudar o ciclo de vida e reprodução do mosquito Anófeles e, ainda, acelerar o ciclo do Plasmódio, que é vetor da doença.

O aumento na temperatura pode aumentar a taxa de reprodução de mosquitos e, como consequência, afetar um maior número de pessoas por esse vetor (GORRIS, 2019; KILPATRICK et al., 2008).

Assim como a malária, outras doenças que envolvem mosquitos em seu ciclo de vida e transmissão também são influenciadas pelo nível de umidade local, uma vez que altas taxas de umidade podem favorecer à proliferação de mosquitos, enquanto que uma menor umidade pode conter a reprodução dos insetos e, por conseguinte, sua transmissão (HUANG et al., 2011; XIANG et al., 2018). Nesse sentido, Patz et al. (2003) ressaltam que a umidade pode influenciar significativamente as doenças suportadas por vetores, particularmente aquelas em que os vetores são mosquitos, como dengue, chikungunya e zika vírus.

A dengue é generalizada nos trópicos, em função do mosquito Aedes aegypti que tem seu ciclo reprodutivo influenciado por altas temperaturas, umidade relativa alta e precipitação frequente, sendo a doença potencializada 
em áreas que passaram por uma rápida urbanização não planejada (WHO, 2020).

Cabe ressaltar aqui que tanto o Aedes aegypti como o Aedes abopictus (mais frequente na Ásia) transmitem dengue, chikungunya, zika e febre amarela, e estão restritos a zonas tropicais e sub-tropicais, sendo o Aedes abopictus encontrado também em zonas temperadas, com temperaturas mais baixas (WHO, 2020). Ainda nesse contexto, as duas espécies mencionadas apresentam um padrão de atividade maior durante o dia, podendo haver atividade durante o início da manhã ou da noite (WHO, 2020).

Da mesma forma, um estresse hídrico, que leva à seca, pode gerar a mortalidade de carrapatos de vida livre, pois a manutenção do nível corporal de água nesses animais é um fator determinante para sua sobrevivência (NEEDHAM \& TEEL, 1991).

Com relação a leishmaniose visceral, Confalonieri (2008) aponta que nas décadas de 70 e 80 , a região do nordeste brasileiro registrou um aumento nos registros dessa doença em razão das secas prolongadas.

De acordo com Patz et al. (2003), pássaros e mamíferos hospedeiros que ocupam um nicho ecológico afetado pela elevação do nível do mar, ao serem ameaçados de extinção, também podem, por consequência, modificar e até eliminar as viroses endêmicas desse habitat.

Para Bouma e Kaay (1994), o risco de uma epidemia de malária na Índia pode aumentar em até cinco vezes nos anos seguintes aos de ocorrência do El Niño, em razão das alterações climáticas que esse evento gera na dinâmica climática da região, em especial na temperatura superficial dos oceanos e na circulação atmosférica.

As alterações nos padrões de chuva tendem a afetar o suprimento de água doce, que, por sua vez, podem impactar nos hábitos de higiene e consequentemente, aumentar o risco de diarreia, que mata 500.000 crianças com menos de 5 anos a cada ano (IPCC, 2014).

Características próprias das estações do ano em determinadas localidades, também estão associadas às doenças infecciosas, como os casos de cólera em Bangladesh, durante a época de monções (fortes chuvas), e os casos de dengue e febre amarela em estações de maior calor e umidade (PATZ et al., 2003).

Com relação à cólera, Cowell (1996) pontua que epidemias de cólera em países em desenvolvimento são regulares em decorrência de condições ecológicas e ambientais influenciadas pelo clima, bem como pelo aumento da temperatura superficial dos oceanos, a qual propicia mais uma série de relações ecológicas diversas. Além disso, a cólera também é influenciada por questões sociais, que podem propiciar um ambiente de vulnerabilidade social e criar situações em que doenças se disseminam mais facilmente, como mencionado por Confalonieri (2008), ao apontar a região do nordeste brasileiro como uma das mais vulneráveis no Brasil para essa doença, a partir da concepção de questões socioeconômicas, epidemiológicas e climáticas envolvidas.

Alguns autores (CHRETIEN et al., 2015; GAGE et al., 2008; GUBLER et al., 2001) ainda ressaltam que o aumento na variabilidade climática e os eventos extremos podem propiciar o surgimento de doenças e produzir mais 
condições ambientais e climáticas que levam às ocorrências delas, demonstrando que há uma dinâmica ainda mais complexa. Nesse sentido, qualquer mudança nas condições ecológicas pode influenciar nas doenças silvestres e, por consequência, ter um impacto potencial na saúde humana (WILSON, 2001).

A presença dos patógenos na natureza é amplamente dependente da interação do hospedeiro com o ambiente externo, e impactos na taxa de transmissão, reprodução e morte de espécies tornam as doenças mais susceptíveis aos efeitos da variabilidade climática (PATZ et al., 2003).

As doenças infecciosas, em especial aquelas transmitidas por vetores, possuem seu próprio habitat natural, da mesma maneira que espécies animais e vegetais (SANTOS et al., 2016). Nesse caso, condições específicas de temperatura, umidade, características da vegetação e solo estão interligadas aos patógenos, vetores e hospedeiros, sendo o homem infectado, normalmente, quando interfere, de algum modo, nessa dinâmica pré-estabelecida (YI et al., 2019; SANTOS et al., 2016; SMITH, 2019).

As espécies também irão variar quanto à sua habilidade em se dispersar em novas áreas geográficas e competir com espécies já existentes no meio, visto que muitas espécies têm habilidades limitadas para se dispersar, enquanto que outras podem se deslocar rapidamente (PITELKA e GROUP, 1997). Assim, uma vez em uma nova área, as espécies também se diferenciarão quanto à sua habilidade em se estabelecer e reproduzir (PATZ et al., 2003).

As diferenças em cada espécie evidenciam como pode ser complexo entender a velocidade e a capacidade das espécies se adaptarem e responderem às mudanças climáticas, ou seja, a carga genética de adaptação existe na maioria das espécies, contudo, o ritmo das mudanças ambientais e climáticas pode superar a capacidade que algumas espécies têm em se moldar ao meio.

De acordo com Joly (2007), as mudanças ambientais e climáticas sofreram uma aceleração significativa nas últimas décadas, explicitando a incompatibilidade entre a velocidade com que ocorrem e o processo evolutivo de plantas e animais para se adaptarem.

Adicionalmente, Alho (2012) pontua que todo sistema formado por patógenos, vetores e hospedeiros sofre perturbações de ordem biótica (como extinção de espécies) e abiótica (com alteração nos ciclos biogeoquímicos), em razão das mudanças climáticas, devendo-se observar com atenção a forma com que o sistema vai se reequilibrar, uma vez que efeitos na saúde humana podem ser sentidos, haja visto que as interações são interconectadas (Fig.1). 


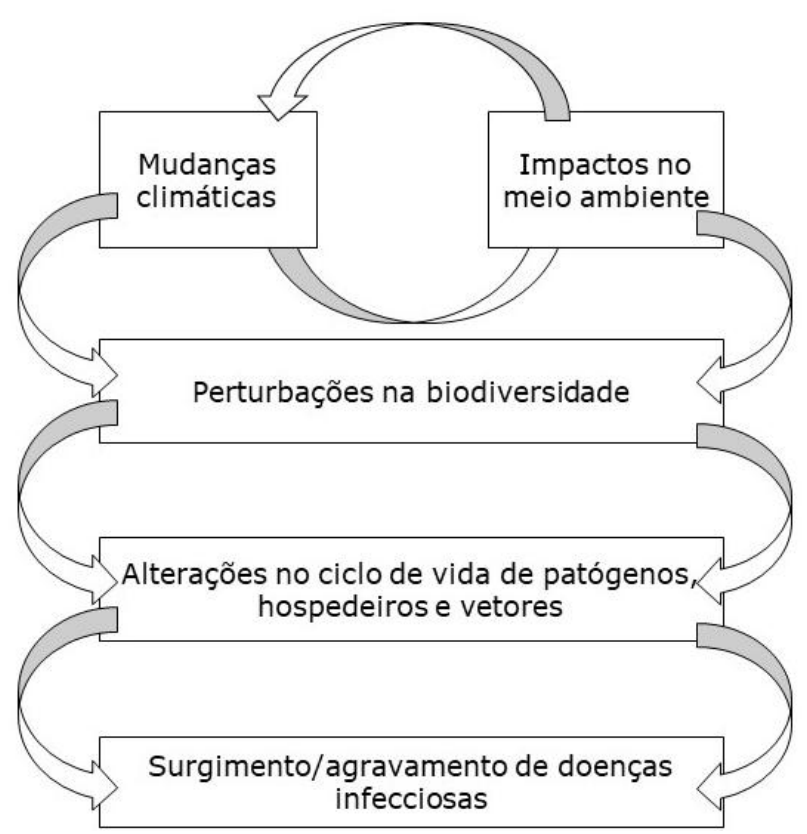

Figura 1 - Esquema do surgimento/agravamento de doenças, como consequência das mudanças climáticas (Fonte: autoria própria).

Assim como as alterações climáticas, existem questões sociais que podem modificar a incidência e o comportamento das doenças, tais como fatores demográficos, migrações, uso de medicamentos e características nutricionais da população. Além destes, e diretamente relacionados às mudanças climáticas, estão o desmatamento, o desenvolvimento agrícola e a urbanização, que ocasionam transformações no uso da terra e impactam o equilíbrio ecológico e ambiental (SANTOS et al., 2016; PATZ et al., 2003; BARCELLOS et al., 2009).

De acordo com Horwood e Greenhill (2016), a primeira pandemia de cólera ocorreu em razão da disseminação da doença através das rotas comerciais entre Índia, China, Indonésia, Europa e Sul da Rússia.

O desmatamento e a fragmentação de habitats na América Latina vêm apresentando um aumento na incidência de leishmaniose visceral associada com um aumento no número de hospedeiros e vetores que se adaptaram ao ambiente periurbano (PATZ, 2000).

No contexto brasileiro, a leishmaniose tegumentar americana tem ocorrência explícita, relacionada à presença do ser humano em ambientes silvestres, bem como em função da expansão das práticas agrícolas (GUIMARÃES et al., 2018). Nesse contexto, Costa (2005) menciona que os surtos epidêmicos dessa doença no Brasil, estão relacionados às mudanças no ambiente, como desmatamento, agricultura e mineração, as quais geram perturbação ecológica e propiciam o contato do homem com os animais silvestres.

O desenvolvimento da agricultura, por sua vez, pode resultar num aumento do uso da água, reduzindo a disponibilidade desta para outros fins e aumentando os locais de reprodução de vetores de doenças. Dessa forma, um aumento na umidade do solo em razão da irrigação, pode provocar um aumento de doenças transmitidas por mosquitos (HARB et al., 1993). 
A SARS-CoV (SARS) identificada em 2002 na China (REPERANT e OSTERHAUS, 2017) teve sua disseminação relacionada aos padrões locais de uso de recursos naturais e a probabilidade de surtos globais da doença aumentam à medida em que houverem fluxos de materiais de origem animal da China para outras partes do mundo (ADGER et al., 2008).

Nesse contexto, os casos de SARS-CoV foram rastreados até indivíduos em Guangdong (província da China) que manipulavam animais vivos vendidos nos mercados de alimentos (ADGER et al., 2008), sugerindo que o comércio de animais silvestres pode impactar a biodiversidade local, bem como elevar o risco de doenças e a vulnerabilidade socioambiental (BELL et al., 2004).

Com relação ao MERS-CoV (MERS), sua identificação em humanos ocorreu em 2012 e considerou que os dromedários existentes na região do Oriente Médio tenham sido os responsáveis pela transmissão do vírus aos humanos, por serem hospedeiros naturais do vírus (FEKADU et al., 2016).

Cabe destacar que o dromedário é considerado uma das espécies animais mais importantes para nutrição em áreas áridas e semiáridas da África Oriental, pois o leite desse animal é usado para consumo ou venda doméstica, sendo o produto mais importante para pastores (FEKADU et al., 2016). Diante das mudanças climáticas e da previsão do agravamento de características locais do clima, ressalta-se a prevalência da espécie de dromedários, visto sua resistência à seca e ao calor (FEKADU et al., 2016).

O surto de SARS-CoV2 (COVID-19), por sua vez, pode ser considerado uma consequência indireta das mudanças ambientais globais (CHAKRABORTY e MAITY, 2020), visto que fatores meteorológicos desempenham uma função importante na transmissão da doença, que tem sua disseminação relacionada a baixas temperaturas e umidade (LIU et al., 2020), sendo a propagação do vírus facilitada em cidades mais populosas (AHMADI et al., 2020).

Além disso, a violação das fronteiras entre animais e humanos devido a urbanização não controlada e a expansão da agricultura, podem ser responsáveis pelas zoonoses de morcegos e outros animais para seres humanos, como nos casos da SARS-CoV, MERS-Cov e SARS-CoV2 (RASTOGI et al., 2020).

Quanto a urbanização, sabe-se que o leste africano foi uma das regiões do planeta que mais rapidamente passou por esse processo, fato que pode ser observado pelo avanço da área urbana em direção ao campo e o estabelecimento de indústrias em áreas interioranas, criando uma interface entre humanos e doenças infecciosas (ALI et al., 2016). Nesse sentido, Ali et al. (2016) comentam que o Ebola, antes considerado um problema isolado de áreas rurais, tornou-se uma questão de saúde pública nas cidades e suas periferias, disseminando-se de modo rápido e desconhecido, em razão da intervenção humana e das novas condições de vida impostas ao meio.

Cabe ressaltar que, anteriormente, a transmissão de doenças infecciosas estava relacionada a regiões urbanas desprovidas de condições básicas de saúde e higiene, e que, atualmente, o problema não se restringe a esses locais, mas relaciona-se a áreas densamente urbanizadas, migrações e ao estreitamento do contato homem-natureza (ALI et al., 2016), evidenciando que há um dinamismo entre os sistemas climático, o ambiente e também com as relações intrínsecas existentes entre eles (RASTOGI et al., 2020). 


\subsection{DOENÇAS INFECCIOSAS: ORIGEM, CARACTERÍSTICAS E CONSIDERAÇÕES AMBIENTAIS}

As doenças vêm influenciando a vida em sociedade e eventos mundiais, sendo classificadas de acordo com os padrões de distribuição espacial e temporal (LACKLAND, 2005).

Nesse sentido, de acordo com Lackland (2005), as doenças consideradas como endêmicas são aquelas em que há prevalência da doença ou condições relacionadas em uma dada população ou área geográfica.

Trata-se por epidemia quando as causas de uma doença ou as condições dela excedem a prevalência normal em uma dada população ou área geográfica, enquanto que o termo pandemia é usado quando uma epidemia ultrapassa fronteiras geopolíticas e, às vezes, tem alcance global (LACKLAND, 2005).

A transmissão de doenças, por sua vez, pode ocorrer de duas formas: entre humanos, ou entre animais e humanos (Fig.2). Didaticamente, para transmissão do primeiro tipo, entre humanos, utiliza-se o termo antroponoses, que caracteriza a transmissão de patógenos através do contato entre humanos (direta) ou por meio de um vetor (indireta). Na transmissão do segundo tipo, chamada de zoonoses, a transmissão pode ser através do contato de humanos com animais (direta) ou através de vetores (indireta) (PATZ et al., 2003).

Quando falamos de zoonoses, é importante ter em mente que muitos agentes infecciosos estão naturalmente disseminados nos animais, que são tidos como reservatórios ou hospedeiros, e que, dessa forma, a infecção em humanos pode ser resultado de um encontro indireto entre humanos e o hospedeiro (PATZ et al., 2003).

O hantavírus, que causa uma síndrome pulmonar, exemplifica como a influência ambiental pode intensificar a transmissão dessa enfermidade aos humanos. Transmitida por roedores (silvestres ou domésticos) assintomáticos, que podem hospedar o vírus por anos (NUNES et al., 2015), o simples aumento do número desses animais por desequilíbrios ecológicos aumenta o contato com humanos, podendo acelerar potencialmente a transmissão do hantavírus (PATZ et al., 2003). 


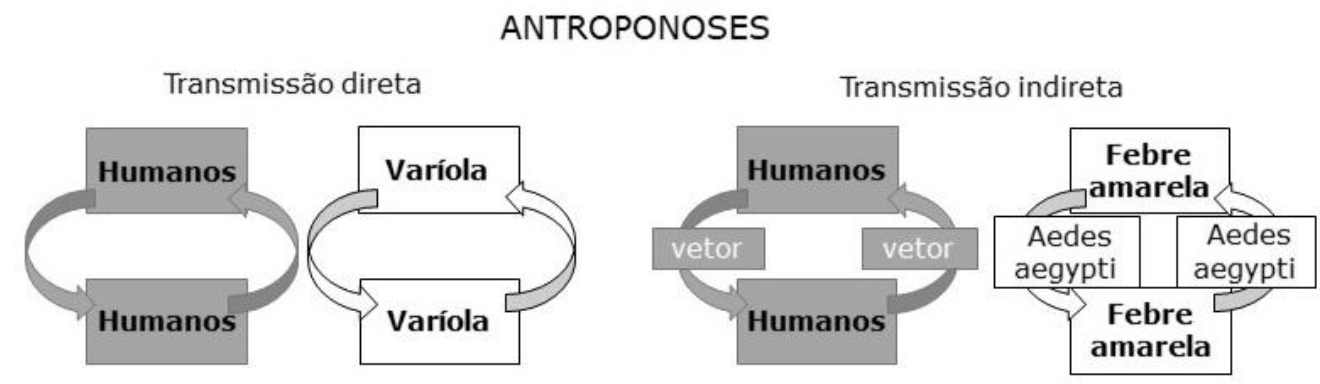

ZOONOSES

Transmissão direta

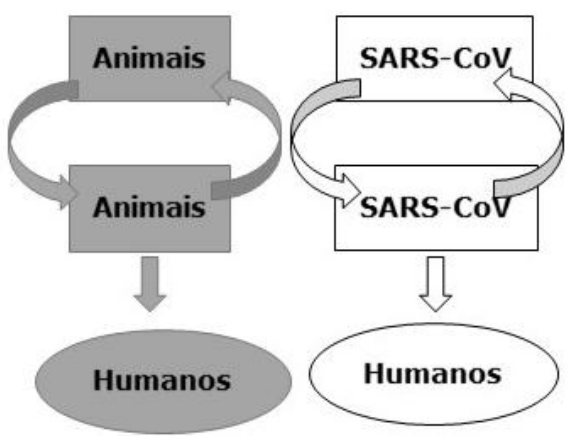

Transmissão indireta
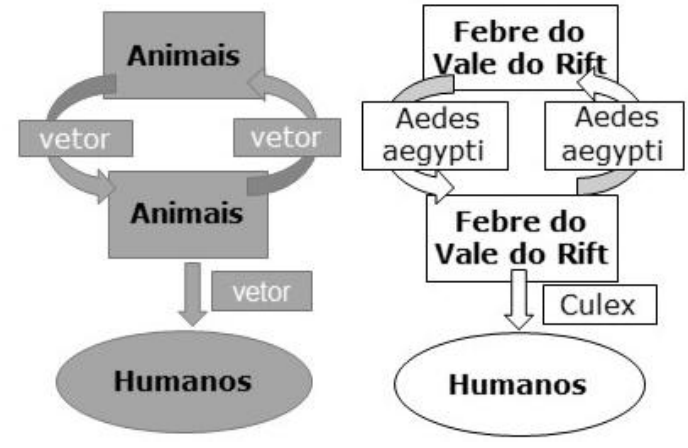

Figura 2 - Ciclo das transmissões de doenças infecciosas (Adaptado de Patz et al., 2003).

A varíola é uma antroponose de transmissão direta, decorrente do contato direto (gotículas de saliva) de pessoas infectadas com pessoas saudáveis (WHO, 2020). De acordo com a World Health Organization (WHO, 2020), a varíola foi erradicada em 1980, após uma campanha mundial de vigilância e vacinação, sendo, de acordo com o órgão de saúde, a única doença infecciosa a alcançar esse patamar.

A Fig.2 evidencia a febre amarela como antroponose de transmissão indireta, a qual comumente infecta viajantes advindos de áreas onde a doença não ocorre, exportando casos para outros países. Contudo, assim como as demais doenças discutidas no texto, a febre amarela somente se espalha em uma nova localidade se encontrar condições climáticas específicas e um hospedeiro adequado (WHO, 2020). Nesse contexto, chikungunya, zika vírus e dengue também apresentam as características descritas acima.

A febre amarela é uma doença com letalidade global que varia de $5 \%$ a $10 \%$, sendo que, nos casos graves, a letalidade pode chegar a $50 \%$ dos casos (VASCONCELOS, 2003).

É importante mencionar que a chikungunya, de acordo com a WHO (2020), é raramente fatal, com sintomas que duram aproximadamente três dias e incluem uma febre abrupta e dores nas articulações. 
A infecção pelo zika vírus não apresenta alta mortalidade, no entanto, há um risco aumentado de complicações neurológicas em adultos e crianças. Além disso, durante a gravidez, pode provocar o nascimento de bebês com microcefalia e outras malformações congênitas, bem como outras complicações durante a gravidez (WHO, 2020).

Com relação à dengue, a incidência global da doença cresceu drasticamente nas últimas décadas. Cerca de metade da população mundial está agora em risco, sendo de 100 a 400 milhões de infectados a cada ano (WHO, 2020).

A febre "Rift Vale" ou febre do Vale do Rift, por sua vez, é descrita como uma zoonose, que inicialmente afeta animais, mas que, também, pode afetar humanos, em razão dos vetores relacionados. Em referência aos animais, essa doença afeta principalmente o gado, provocando efeitos significantes na economia devido às altas taxas de mortalidade em animais jovens e fêmeas grávidas (WHO, 2020). Em seres humanos, a febre do Vale do Rift apresenta uma taxa de mortalidade baixa, visto que os casos fatais, no geral, são inferiores a $1 \%($ WHO, 2020).

Zoonoses e antroponoses transmitidas por vetores dependem da ecologia de animais não humanos e são especialmente sensíveis aos efeitos das mudanças ecológicas (Patz et al., 2003). Estima-se que $75 \%$ das doenças infeciosas emergentes tem humanos envolvidos com patógenos de origem animal (TAYLOR et al., 2001).

Nesse contexto, são caracterizadas algumas das doenças influenciáveis pelas mudanças climáticas no Quadro 1.

Quadro 1 - Caracterização das doenças infecciosas influenciáveis pelas mudanças climáticas

\begin{tabular}{|c|c|c|c|c|c|}
\hline Doença & Origem & $\begin{array}{l}1^{\circ} \text { caso em } \\
\text { humanos }\end{array}$ & Transmissão & $\begin{array}{l}\text { Fatores } \\
\text { climáticos e } \\
\text { ambientais } \\
\text { relacionados }\end{array}$ & $\begin{array}{c}\text { Alcance } \\
\text { da } \\
\text { doença }\end{array}$ \\
\hline 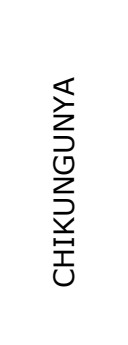 & $\begin{array}{c}\text { Originário de } \\
\text { primatas não } \\
\text { humanos na África, } \\
\text { entre } 300 \text { e } 500 \text { anos } \\
\text { atrás (VOLK et al., } \\
\text { 2010; BRAACK et al., } \\
\text { 2018) }\end{array}$ & $\begin{array}{l}\text { Reconhecida } \\
\text { pela } 10 \text { vez } \\
\text { em } 1952, \text { no } \\
\text { sul da } \\
\text { Tanzânia } \\
\text { (WHO, } \\
\text { 2020) }\end{array}$ & $\begin{array}{l}\text { Transmitida aos } \\
\text { humanos pelo } \\
\text { mosquito Aedes } \\
\text { aegypti ou } \\
\text { Aedes } \\
\text { albopictus } \\
\text { (WHO, 2020) }\end{array}$ & $\begin{array}{c}\text { - altas taxas de } \\
\text { precipitação e } \\
\text { temperatura } \\
\text { - umidade } \\
\text { elevada } \\
\text { - urbanização } \\
\text { - desmatamento } \\
\text { - avanço da } \\
\text { fronteira } \\
\text { agrícola }\end{array}$ & $\begin{array}{l}\text { Endêmica } \\
\text {, mas já } \\
\text { houve } \\
\text { epidemias } \\
\text { (WHO, } \\
\text { 2020) }\end{array}$ \\
\hline
\end{tabular}




\begin{tabular}{|c|c|c|c|c|c|}
\hline Doença & Origem & $\begin{array}{l}10 \text { caso em } \\
\text { humanos }\end{array}$ & Transmissão & $\begin{array}{c}\text { Fatores } \\
\text { climáticos e } \\
\text { ambientais } \\
\text { relacionados }\end{array}$ & $\begin{array}{c}\text { Alcance } \\
\text { da } \\
\text { doença }\end{array}$ \\
\hline 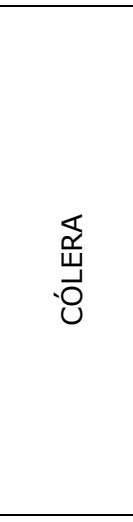 & $\begin{array}{l}\text { Surgiu durante o } \\
\text { século XIX no delta } \\
\text { do Rio Ganges } \\
\text { (IIndia) (WHO, 2020) }\end{array}$ & $\begin{array}{c}\text { A } 10 \\
\text { pandemia } \\
\text { ocorreu em } \\
1817, \text { sem } \\
\text { relatos } \\
\text { precisos do } \\
10 \text { caso em } \\
\text { humanos } \\
\text { (HORWOOD } \\
\text { e } \\
\text { GREENHILL, } \\
2016 \text { ) }\end{array}$ & $\begin{array}{l}\text { Transmitida por } \\
\text { alimentos ou } \\
\text { água } \\
\text { contaminadas } \\
\text { pela bactéria } \\
\text { Vibrio cholerae } \\
\text { (WHO, 2020) }\end{array}$ & $\begin{array}{l}\text { - aumento da } \\
\text { temperatura dos } \\
\text { oceanos } \\
\text { - urbanização } \\
\text { - eventos } \\
\text { extremos }\end{array}$ & 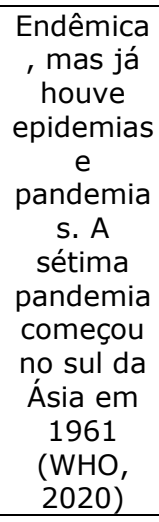 \\
\hline 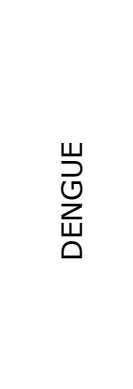 & $\begin{array}{l}\text { Originalmente o vírus } \\
\text { circulava em } \\
\text { primatas não } \\
\text { humanos, na África } \\
\text { (BRAACK et al., } \\
\text { 2018) }\end{array}$ & $\begin{array}{l}\text { A dengue } \\
\text { grave foi } \\
\text { reconhecida } \\
\text { na década } \\
\text { de } 1950, \text { em } \\
\text { epidemias } \\
\text { nas Filipinas } \\
\text { e na } \\
\text { Tailândia } \\
\text { (WHO, } \\
2020)\end{array}$ & $\begin{array}{l}\text { Transmitida aos } \\
\text { humanos pelo } \\
\text { mosquito Aedes } \\
\text { aegypti ou } \\
\text { Aedes } \\
\text { albopictus } \\
\text { (WHO, 2020) }\end{array}$ & $\begin{array}{l}\text { - altas taxas de } \\
\text { precipitação e } \\
\text { temperatura } \\
\text { - umidade } \\
\text { elevada } \\
\text { - urbanização } \\
\text { - desmatamento } \\
\text { - avanço da } \\
\text { fronteira } \\
\text { agrícola }\end{array}$ & $\begin{array}{l}\text { Endêmica } \\
\text {, mas já } \\
\text { houve } \\
\text { epidemias } \\
\text { (WHO, } \\
\text { 2020) }\end{array}$ \\
\hline 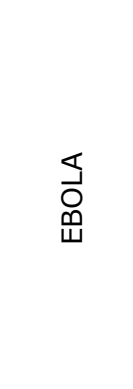 & $\begin{array}{l}\text { Acredita-se que o } \\
\text { vírus seja originário } \\
\text { de morcegos, na } \\
\text { África (REPERANT e } \\
\text { OSTERHAUS, 2017) }\end{array}$ & $\begin{array}{c}\text { Identificada } \\
\text { em humanos } \\
\text { pela } 10 \text { vez, } \\
\text { em 1976, na } \\
\text { África (WHO, } \\
2020 \text { ) }\end{array}$ & $\begin{array}{l}\text { Transmitida às } \\
\text { pessoas a partir } \\
\text { de animais } \\
\text { selvagens } \\
\text { (morcegos, } \\
\text { porcos-espinhos } \\
\text { e primatas não } \\
\text { humanos) }\end{array}$ & $\begin{array}{l}\text { - alteraç̃̃es nos } \\
\text { padrões de } \\
\text { precipitação } \\
\text { - alterações na } \\
\text { frequência e } \\
\text { intensidade das } \\
\text { tempestades } \\
\text { - eventos } \\
\text { extremos } \\
\text { - urbanização }\end{array}$ & $\begin{array}{c}\text { Considera } \\
\text { da } \\
\text { epidêmica } \\
\text {. Houve } \\
\text { uma } \\
\text { pandemia } \\
\text { de Ebola } \\
\text { durante } \\
2014 \\
(\text { WHO, } \\
2020)\end{array}$ \\
\hline 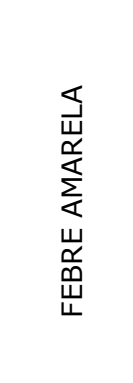 & $\begin{array}{l}\text { Originalmente, o } \\
\text { vírus circulava em } \\
\text { primatas não } \\
\text { humanos da África } \\
\text { (BRAACK et al., } \\
\text { 2018) }\end{array}$ & $\begin{array}{c}\text { Indefinido, } \\
\text { mas há } \\
\text { relatos de } \\
\text { febre } \\
\text { amarela no } \\
\text { século XIX } \\
\text { (FIERRO- } \\
\text { HERNÁNDEZ } \\
\text { e AYALA- } \\
\text { ZÚÑIGA, } \\
\text { 2016) }\end{array}$ & $\begin{array}{l}\text { Transmitida aos } \\
\text { humanos pelo } \\
\text { mosquito Aedes } \\
\text { aegypti ou } \\
\text { Aedes } \\
\text { albopictus } \\
\text { (WHO, 2020) }\end{array}$ & $\begin{array}{l}\text { - altas taxas de } \\
\text { precipitação e } \\
\text { temperatura } \\
\text { - umidade } \\
\text { elevada } \\
\text { - urbanização } \\
\text { - desmatamento } \\
\text { - avanço da } \\
\text { fronteira } \\
\text { agrícola }\end{array}$ & $\begin{array}{c}\text { Atualment } \\
\text { e } \\
\text { endêmica, } \\
\text { mas já } \\
\text { houve } \\
\text { epidemias } \\
\text { (WHO, } \\
2020 \text { ) }\end{array}$ \\
\hline
\end{tabular}




\begin{tabular}{|c|c|c|c|c|c|}
\hline Doença & Origem & $\begin{array}{c}10 \text { caso em } \\
\text { humanos }\end{array}$ & Transmissão & $\begin{array}{c}\text { Fatores } \\
\text { climáticos e } \\
\text { ambientais } \\
\text { relacionados }\end{array}$ & $\begin{array}{c}\text { Alcance } \\
\text { da } \\
\text { doença }\end{array}$ \\
\hline 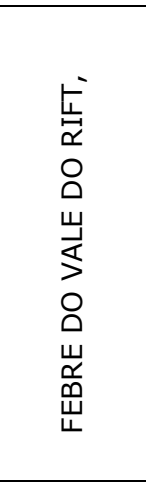 & $\begin{array}{l}\text { Originária de animais } \\
\text { como gado, ovelha e } \\
\text { cabra, no continente } \\
\text { africano, desde } 1931 \\
\text { (BRAACK et al., } \\
\text { 2018) }\end{array}$ & $\begin{array}{c}\text { Data incerta, } \\
\text { mas casos } \\
\text { severos da } \\
\text { doença } \\
\text { foram } \\
\text { relatados } \\
\text { nos anos } \\
2000 \text { (Arábia } \\
\text { Saudita e } \\
\text { Yemen) } \\
\text { (WHO, } \\
2020 \text { ) }\end{array}$ & $\begin{array}{c}\text { Transmitida } \\
\text { pelo contato } \\
\text { direto ou } \\
\text { indireto de } \\
\text { pessoas com o } \\
\text { sangue ou } \\
\text { órgãos de } \\
\text { animais } \\
\text { infectados, ou } \\
\text { através da } \\
\text { picada do } \\
\text { mosquito Aedes } \\
\text { ou Culex (WHO, } \\
2020)\end{array}$ & $\begin{array}{l}\text {-El Niño } \\
\text { - elevado } \\
\text { volume de } \\
\text { chuvas } \\
\text { - alteração na } \\
\text { circulação } \\
\text { atmosférica }\end{array}$ & $\begin{array}{c}\text { Endêmica } \\
\text { ' mas já } \\
\text { houve } \\
\text { epidemias } \\
\text { (WHO, } \\
\text { 2020) }\end{array}$ \\
\hline 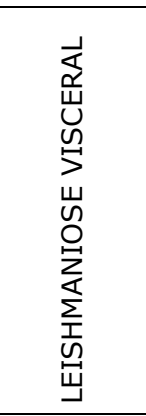 & $\begin{array}{c}\text { O continente africano } \\
\text { é considerado o local } \\
\text { de origem do } \\
\text { protozoário } \\
\text { Leishmania, com } \\
\text { evidências deste } \\
\text { desde a Era } \\
\text { Mesozoica } \\
\text { (AKHOUNDI et al., } \\
\text { 2016) }\end{array}$ & $\begin{array}{l}\text { Data incerta, } \\
\text { mas o } 10 \\
\text { caso no } \\
\text { Sudão } \\
\text { ocorreu em } \\
1904 \text { (HAILU } \\
\text { et al., 2016) }\end{array}$ & $\begin{array}{c}\text { Transmitida pela } \\
\text { picada de } \\
\text { flebotomíneos } \\
\text { fêmeas } \\
\text { infectadas pelo } \\
\text { protozoário } \\
\text { Leishmania } \\
\text { (WHO, 2020) }\end{array}$ & $\begin{array}{c}\text {-seca } \\
\text {-inundações } \\
\text {-alterações nos } \\
\text { padrões de } \\
\text { temperatura, } \\
\text { umidade e } \\
\text { precipitação } \\
\text {-desmatamento } \\
\text {-urbanização } \\
\text {-avanço da } \\
\text { fronteira } \\
\text { agrícola } \\
\end{array}$ & $\begin{array}{c}\text { Endêmica } \\
\text { ' mas já } \\
\text { houve } \\
\text { epidemias } \\
\text { (WHO, } \\
\text { 2020) }\end{array}$ \\
\hline 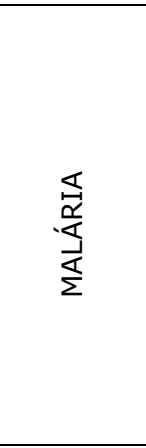 & $\begin{array}{c}\text { Causada pelo } \\
\text { parasita plasmodium } \\
\text { derivado de parasitas } \\
\text { de primatas não } \\
\text { humanos, da época } \\
\text { em que os } \\
\text { hominídeos } \\
\text { colonizaram a Ásia } \\
\text { (WHO, 2020) }\end{array}$ & 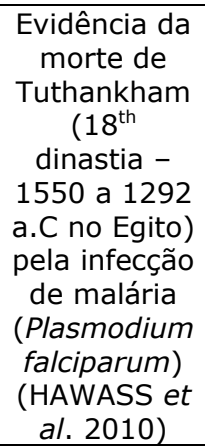 & $\begin{array}{l}\text { Transmitida às } \\
\text { pessoas através } \\
\text { da picada do } \\
\text { mosquito } \\
\text { Anófeles (WHO, } \\
\text { 2020) }\end{array}$ & $\begin{array}{l}\text { - altas taxas de } \\
\text { precipitação e } \\
\text { temperatura } \\
\text { - umidade } \\
\text { elevada } \\
\text { - urbanização } \\
\text { - desmatamento } \\
\text {-avanço da } \\
\text { fronteira } \\
\text { agrícola }\end{array}$ & $\begin{array}{c}\text { Atualment } \\
e \\
\text { endêmica, } \\
\text { mas } \\
\text { houve } \\
\text { epidemias } \\
\text { (WHO, } \\
2020 \text { ) }\end{array}$ \\
\hline 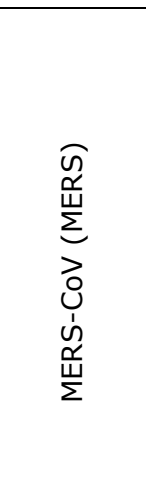 & $\begin{array}{c}\text { Origem } \\
\text { desconhecida, mas } \\
\text { análises de genomas } \\
\text { do vírus sugerem que } \\
\text { ele tenha se } \\
\text { originado em } \\
\text { morcegos (da África) } \\
\text { e o transmitiram aos } \\
\text { dromedários (WHO, } \\
2020 \text { ) }\end{array}$ & $\begin{array}{c}\text { Identificada } \\
\text { pela } 10 \text { vez } \\
\text { em 2012, na } \\
\text { Arábia } \\
\text { Saudita } \\
\text { (WHO, } \\
\text { 2020) }\end{array}$ & $\begin{array}{c}\text { Estudos } \\
\text { sugerem que } \\
\text { dromedários são } \\
\text { hospedeiros de } \\
\text { MERS-CoV, mas } \\
\text { o modo como o } \\
\text { vírus foi } \\
\text { transmitido aos } \\
\text { humanos é } \\
\text { desconhecido } \\
\text { (WHO, 2020) }\end{array}$ & $\begin{array}{c}\text { Não é possível } \\
\text { inferir fatores } \\
\text { climáticos ou } \\
\text { ambientais } \\
\text { associados, mas } \\
\text { menciona-se } \\
\text { fatores de } \\
\text { cunho social } \\
\text { como } \\
\text { características } \\
\text { nutricionais da } \\
\text { população** e o } \\
\text { comércio de } \\
\text { animais* }\end{array}$ & $\begin{array}{l}\text { Epidêmica } \\
\text { (WHO, } \\
2020)\end{array}$ \\
\hline
\end{tabular}




\begin{tabular}{|c|c|c|c|c|c|}
\hline Doença & Origem & $\begin{array}{l}10 \text { caso em } \\
\text { humanos }\end{array}$ & Transmissão & $\begin{array}{c}\text { Fatores } \\
\text { climáticos e } \\
\text { ambientais } \\
\text { relacionados }\end{array}$ & $\begin{array}{l}\text { Alcance } \\
\text { da } \\
\text { doença }\end{array}$ \\
\hline 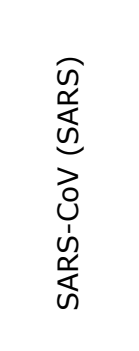 & $\begin{array}{l}\text { Provavelmente } \\
\text { originária de } \\
\text { morcegos no } \\
\text { continente asiático } \\
\text { (REPERANT e } \\
\text { OSTERHAUS, 2017) }\end{array}$ & $\begin{array}{c}\text { Identificada } \\
\text { na província } \\
\text { de } \\
\text { Guangdong } \\
\text { (China), no } \\
\text { final de } 2002 \\
\text { (CHAKRABO } \\
\text { RTY e } \\
\text { MAITY, } \\
\text { 2020) }\end{array}$ & $\begin{array}{l}\text { Transmitida aos } \\
\text { humanos no } \\
\text { mercado de } \\
\text { animais na } \\
\text { China, a partir } \\
\text { de carnes } \\
\text { infectadas (LI et } \\
\text { al., 2005) }\end{array}$ & $\begin{array}{l}\text { - urbanização } \\
\text { - avanço da } \\
\text { fronteira } \\
\text { agrícola } \\
\text { - comércio de } \\
\text { animais } \\
\text { silvestres* } \\
\text { - baixa } \\
\text { temperatura e } \\
\text { umidade }\end{array}$ & $\begin{array}{c}\text { Epidêmica } \\
\text { (WHO, } \\
\text { 2020) }\end{array}$ \\
\hline 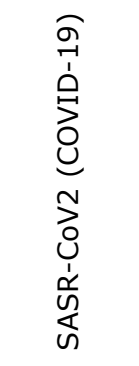 & $\begin{array}{c}\text { Provavelmente } \\
\text { originária de um } \\
\text { morcego, contudo, } \\
\text { considera-se que } \\
\text { houve um hospedeiro } \\
\text { intermediário, no } \\
\text { continente asiático } \\
\text { (RASTOGI et al., } \\
\text { 2020) }\end{array}$ & $\begin{array}{l}\text { Os primeiros } \\
\text { casos foram } \\
\text { identificados } \\
\text { em 2019, na } \\
\text { cidade de } \\
\text { Wuhan } \\
\text { (China) }\end{array}$ & $\begin{array}{l}\text { Transmitida aos } \\
\text { humanos por } \\
\text { um animal } \\
\text { desconhecido }\end{array}$ & $\begin{array}{c}\text { - relações com } \\
\text { fatores } \\
\text { ambientais e } \\
\text { climáticos } \\
\text { incerta, } \\
\text { necessitando de } \\
\text { mais estudos, } \\
\text { de acordo com } \\
\text { O'Reilly et al. } \\
\text { (2020). }\end{array}$ & $\begin{array}{c}\text { Pandêmic } \\
\text { a } \\
\text { atualment } \\
\text { e (WHO, } \\
2020)\end{array}$ \\
\hline 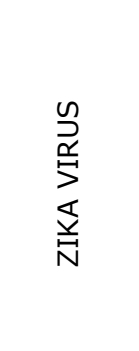 & $\begin{array}{c}\text { Originária de } \\
\text { primatas não } \\
\text { humanos, sendo } \\
\text { identificado em } 1947 \\
\text { em Uganda - África } \\
(\text { WHO, 2020) }\end{array}$ & $\begin{array}{c}\text { Identificada } \\
\text { em } 1952 \text { em } \\
\text { Uganda - } \\
\text { África (WHO, } \\
2020)\end{array}$ & $\begin{array}{l}\text { Transmitida aos } \\
\text { humanos pelo } \\
\text { mosquito Aedes } \\
\text { aegypti ou } \\
\text { Aedes } \\
\text { albopictus } \\
\text { (WHO, 2020) }\end{array}$ & $\begin{array}{l}\text { - altas taxas de } \\
\text { precipitação e } \\
\text { temperatura } \\
\text { - umidade } \\
\text { elevada } \\
\text { - urbanização } \\
\text { - desmatamento } \\
\text {-avanço da } \\
\text { fronteira } \\
\text { agrícola }\end{array}$ & $\begin{array}{l}\text { Endêmica } \\
\text {, mas já } \\
\text { houve } \\
\text { epidemias } \\
\text { (WHO, } \\
2020)\end{array}$ \\
\hline
\end{tabular}

*O comércio de animais, em especial os silvestres, pode provocar alterações na biodiversidade de uma determinada região, propiciando o surgimento de doenças.

**O padrão alimentar de algumas populações está baseado em animais silvestres e mamíferos domesticados, que podem ser hospedeiros de doenças infecciosas.

Atualmente, aproximadamente $90 \%$ das mortes por malária no mundo ocorrem na África Subsaariana, isso porque a maioria das infecções no continente são causadas pelo Plasmodium falciparum (o mais perigoso dos quatro parasitas da malária humana), assim como também porque o vetor mais eficaz da malária, o mosquito Anófeles, é o mais difundido na África e o mais difícil de controlar (WHO, 2002). Nesse sentido, estima-se que um milhão de pessoas na África morram de malária a cada ano, e a maioria delas são crianças menores de cinco anos, sendo que a malária possui tratamento e é possível preveni-la a partir do controle dos vetores da doença (WHO, 2002).

É interessante destacar que a malária pode ser considerada como uma das doenças infecciosas mais antigas na história da humanidade, em vista dos relatos de mortes ocasionadas pelo parasita plasmodium desde 1550 a.C. Além da malária, evidências fósseis indicam que a Leishmania pode ter surgido durante o Cretáceo (há aproximadamente 100 Ma), na Era Mesozoica, evoluindo 
durante o Cenozoico, juntamente com seus vetores e hospedeiros e dispersando-se durante o período Neogeno (Eoceno) (AKHOUNDI et al., 2016).

Com relação às leishmanioses, é possível destacar três formas principais da doença, como a leishmaniose visceral (forma mais grave), a tegumentar (a mais comum) e a mucocutânea (WHO, 2002).

A leishmaniose visceral, descrita no Quadro 1, é fatal se não for tratada em mais de $95 \%$ dos casos, contabilizando a maioria das ocorrências no Brasil, na África Oriental e na Índia. Estima-se que 50.000 a 90.000 novos casos de leishmaniose visceral ocorram em todo o mundo anualmente, evidenciando, como esta, continua sendo uma das principais doenças parasitárias com potencial de mortalidade e surtos frequentes (WHO, 2002).

Pesquisadores estimam que há entre 1,3 e 4 milhões de casos de cólera a cada ano, sendo contabilizadas de 21 mil a 143 mil mortes em todo o mundo (ALI et al., 2015). Com relação aos sintomas, a cólera pode demorar de $12 \mathrm{~h}$ a 5 dias após a ingestão de água ou alimentos contaminados para manifestar sintomas, sendo mais perigosa nas crianças ao causar diarreia e forte desidratação (AZMAN et al., 2012).

O Ebola, por sua vez, é considerada uma doença com alta mortalidade (REPERANT e OSTERHAUS, 2017), o que corrobora com o fato do surto de Ebola no oeste da África, entre 2014 e 2016, ter sido o maior e mais complexo desde que o vírus foi descoberto (WHO, 2020).

Os surtos anteriores ao Ebola, como o surto global de coronavírus da síndrome respiratória aguda grave (SARS-CoV) de 2002, que se originou na província de Guangdong na China, ou o surto da síndrome respiratória do Oriente Médio (MERS-CoV), originário da Arábia Saudita, tiveram uma taxa de mortalidade de $9,6 \%$ e 37\%, respectivamente (CHAKRABORTY e MAITY, 2020).

A falta de detalhes sobre a MERS-CoV e os modos de transmissão entre animal e humanos demonstram que os fatores determinantes para se compreender a epidemia dessa doença ainda permanecem mal caracterizados (CAUCHEMEZ et al., 2016; REPERANT e OSTERHAUS, 2017).

Ressalta-se que são necessárias mais pesquisas para entender os fatores de risco que facilitam a exposição humana ao vírus dos dromedários, como sistemas agrícolas, comportamento humano, fatores agroecológicos, alterações climáticas, entre outros (FAO, 2017). Além disso, mudanças nas características da doença, como disseminação ou persistência, também podem ter relação com a intensificação da pecuária, alterações climáticas e mudanças nos padrões de comércio internacional (FAO, 2017).

O sétimo coronavírus conhecido por infectar seres humanos está relacionado aos surtos de SARS-CoV2, que tiveram como foco o mercado de alimentos em Wuhan, na China (CHAKRABORTY e MAITY, 2020). Apesar da grande quantidade de informação acerca do novo coronavírus, ainda se faz importante saber muito mais sobre sua evolução, transmissão e genoma (RASTOGI et al., 2020).

A pandemia de SARS-CoV2 é considerada a calamidade de saúde global mais crucial do século XXI e o maior desafio que a humanidade já enfrentou desde a Segunda Guerra Mundial. É interessante destacar, o significado do nome COVID-19 dado ao vírus SARS-CoV2, em que "CO" significa corona, "VI" 
vem de vírus e "D" de doença, enquanto que 19 representa o ano de sua ocorrência (RASTOGI et al., 2020).

Ainda quanto a SARS-CoV2, O'Reilly et al. (2020) comentam que a sazonalidade não pode ser um fator diretamente relacionado a capacidade dessa doença em se disseminar, tendo em vista seu caráter pandêmico, sendo preciso estudos adicionais para entendê-la, que considerem o impacto da variabilidade climática e a poluição do ar, além de se considerar fatores como movimento populacional, susceptibilidade à transmissão e vigilância de infecções nas diferentes localidades do globo.

A partir da observação do Quadro 1, nota-se que os mosquitos são vetores de muitas doenças infecciosas, enquanto que outras têm nos morcegos seu hospedeiro. Entretanto, os morcegos, mosquitos e qualquer outro animal não podem ser responsabilizados pela disseminação de infecções virais aos seres humanos (RASTOGI et al., 2020). É preciso ter consciência de que há uma invasão de habitats por parte dos seres humanos e, por isso, torna-se necessária a construção de uma visão mais vigilante e holística em relação ao meio ambiente, bem como de uma consciência ambiental (RASTOGI et al., 2020).

Diante do exposto, é preciso compreender que há um padrão quanto às doenças infecciosas e o surgimento delas, o qual evidencia que a pressão das mudanças climáticas e ambientais sobre o meio é um fator relevante, ainda que não seja possível dimensionar até que ponto estes fatores podem promover, por si só o aparecimento das doenças, ou se estão associadas a outros aspectos, como a capacidade de mutação do vírus.

\section{VULNERABILIDADE SOCIOAMBIENTAL}

As condições climáticas e os efeitos das mudanças climáticas globais são específicos de cada localidade e seus impactos estão diretamente relacionados ao contexto social (ERIKSEN e SELBOE, 2012). Além disso, deve-se considerar fatores socioeconômicos, o estado de saúde subjacente da população, a localização geográfica, o comportamento social e a capacidade do governo em responder às mudanças, visto serem questões cruciais relacionadas à vulnerabilidade, concebendo que qualquer um dos pontos mencionados pode influenciar na saúde humana (SALVADOR et al., 2020).

Dessa forma, pode-se inferir que os impactos das mudanças climáticas na saúde humana são amplos, complexos e amplamente adversos (BERRANGFORD et al., 2012). Além disso, os impactos das mudanças climáticas não serão sentidos de maneira uniforme através das diferentes regiões do planeta (FLATO et al., 2017), da mesma forma que seus efeitos na saúde.

Esses impactos podem ser imediatos, como através de modificações na magnitude e inclusive, na frequência de eventos climáticos, ou podem se manifestar por vias mais distais, como uma mudança na segurança alimentar ou a distribuição de vetores de doenças (BERRANG-FORD et al., 2012).

No entanto, a avaliação da WHO (2020), considerando unicamente o cenário dos possíveis impactos na saúde e assumindo um contínuo crescimento econômico, concluiu que as mudanças climáticas acarretarão, adicionalmente, cerca de 250.000 mortes por ano, entre 2030 e 2050, sendo que, do total de 
mortes descritas, a WHO espera que 38 mil seja de idosos expostos ao calor, 48 mil em razão de diarreia, 60 mil pela malária e 95 mil por conta da desnutrição infantil.

Nesse sentido, vem sendo reconhecida a importância de responder às mudanças e impactos ambientais e sociais, considerando a capacidade de adaptação aos eventos do clima ao longo do tempo, e a partir da compreensão dos fatores e dos efeitos a eles relacionados (ERIKSEN e SELBOE, 2012).

De acordo com a WHO (2020), todas as populações serão afetadas pelas mudanças climáticas, mas algumas são mais vulneráveis que outras, tais como populações que vivem em regiões isoladas, em arquipélagos ou regiões costeiras, assim como em grandes cidades e regiões montanhosas, além das regiões polares. A região da Mesoamérica (que engloba o sul do México, El Salvador, Belize, Guatemala, bem como porções ocidentais da Costa Rica, Honduras e Nicarágua) se destaca por estar localizada em uma zona com rica biodiversidade e totalmente exposta aos efeitos das mudanças climáticas, apresentando alto nível de vulnerabilidade ambiental e também social, em razão do alto nível de pobreza dos países que compõem essa região (GUTIÉRREZ e ESPINOSA, 2010).

As crianças, em particular, as que residem em países com baixo índice de desenvolvimento, estão entre as mais vulneráveis aos riscos à saúde resultantes das mudanças climáticas e ficarão mais expostas às consequências destas (WHO, 2020), devido à baixa capacidade fisiológica e cognitiva (JANKOWSKA et al., 2012).

Também se espera que os efeitos na saúde sejam mais graves em idosos e pessoas com enfermidades ou condições médicas pré-existentes, assim como em localidades em que a infraestrutura de saúde seja menos desenvolvida para lidar e responder às necessidades locais, como nos países em desenvolvimento (WHO, 2020).

Assim, conhecer e aplicar o conceito de vulnerabilidade é essencial para estudar as populações que apresentam maior risco socioambiental e com isso, agir conforme às necessidades destas, com relação as medidas de proteção e adaptação contra os efeitos diversos do clima na saúde, concebendo-se ainda que as populações urbanas tendem a ser mais vulneráveis, sobretudo as marginalizadas (CONFALONIERI, 2008).

Destaca-se, nesse sentido, que o termo vulnerabilidade é considerado em função da exposição, sensibilidade e capacidade adaptativa de uma região, população ou grupo em relação ao meio ambiente e às mudanças climáticas (BARCELLOS et al., 2016; DOGRA et al., 2019). A definição do IPCC, por sua vez, salienta que vulnerabilidade é "o grau de suscetibilidade de indivíduos e sistemas ou da incapacidade de resposta aos efeitos adversos da mudança climática, incluindo-se a variabilidade climática e os eventos extremos" (IPCC, 2001).

Segundo Mendonça (2010), a formação de megacidades em países da América Latina, África e Ásia acentuam problemáticas de ordem social, econômica e ambiental já existentes e potencializadas pelas mudanças climáticas, por concentrarem um intenso processo de urbanização, crescimento demográfico e degradação ambiental. 
Dessa forma, a vulnerabilidade social se sobressai em áreas urbanas por concentrarem os maiores contrastes sociais e apresentarem uma grande parcela populacional vivendo e atuando junto ao meio ambiente num dado local, propiciando, por conseguinte, uma maior escala de efeito das mudanças climáticas sobre essas áreas (OJIMA e HOGAN, 2008a), e devendo-se, portanto, ter atenção com o desenvolvimento de políticas públicas para esses grandes centros (OJIMA e HOGAN, 2008b)

Num cenário global, um elevado nível de vulnerabilidade é atribuído à Ásia $(74,6 \%)$, seguida pela África $(19,6 \%)$, por se considerar as altas taxas de crescimento populacional e o intenso desenvolvimento de infraestrutura, a partir dos quais compreende-se que a pressão nessas localidades aumentará continuamente (NGUYEN e LIOU, 2019). Corroborando ao exposto, o estudo de Yi et al. (2019) salienta que a China é o país que mais contribui com doenças infecciosas no mundo e que, dessas, grande parte é sensível ao clima.

Cabe salientar, que o meio ambiente sofre maior pressão antrópica em localidades da Ásia e África, porque nessas regiões a população depende significativamente de bens e serviços dos ecossistemas e de recursos naturais (NGUYEN e LIOU, 2019). Além disso, o continente africano sofre com conflitos por territórios de cunho étnico, político e religioso, que culminam em agravamento das questões econômicas já instáveis, aumento nos processos migratórios e perturbações ambientais, gerando escassez de terras e ampliando problemas socioeconômicos (BONNE, 2017).

O sul da Ásia e sudeste asiático, também são duas regiões caracterizadas por diversidades sociais, políticas, étnicas e religiosas, que propiciam o desenvolvimento de crises humanitárias (Nordsqvist e Krampe, 2018) sem precedentes, sendo ainda, regiões consideradas vulneráveis quanto às mudanças climáticas. Dado o exposto, Adams et al. (2018) ressaltam que é preciso mais estudos para entender como essas regiões são afetadas pela relação entre mudanças climáticas e os conflitos sociais.

Nesse sentido, Qayyum et al. (2021) estudaram sobre a ocorrência dos conflitos armados e atividades militares no continente asiático com relação a contaminação dos recursos naturais pelo uso de minas terrestres e produtos químicos, por exemplo, evidenciando a partir de seu trabalho que tais atividades geram grandes impactos ao meio ambiente e degradação da camada de ozônio, pelo lançamento de poluentes na atmosfera.

Nguyen e Liou (2019) mencionam ainda, que esses continentes possuem uma longa história de pastoreio e práticas agrícolas intensivas em regiões menos desenvolvidas, que acarretaram a degradação e erosão do solo. Adicionalmente ao exposto, os mesmos autores pontuam que, devido às características topográficas e os efeitos das mudanças climáticas, a Ásia e a África são significativamente influenciadas por frequentes riscos naturais, potencializando os distúrbios ambientais.

Jankowska et al. (2012) pontuam que mais de 200 milhões de pessoas permanecem desnutridas nos países da África Subsaariana e esse número pode crescer em 12 milhões à medida que as temperaturas aumentam e os rendimentos das colheitas decaem. Nesse sentido, os mesmos autores sugerem que problemas de saúde pública relacionados à desnutrição continuarão 
estendendo-se à medida que a agricultura e a segurança alimentar se tornarem cada vez mais impactadas por eventos climáticos.

O IPCC, por sua vez, prevê com grande confiança que as mudanças climáticas, entre outras tensões, reduzirão a produção agrícola, agravarão o estresse hídrico e alterarão a ecologia dos vetores de doenças infecciosas na África e Ásia, através de alterações nos padrões de temperatura e precipitação (BERRANG-FORD et al., 2012).

Ali et al. (2016) alertam que em 2030 projeta-se que as áreas urbanas no planeta cubram 1,2 milhões de quilômetros quadrados, representando duas vezes mais do que havia nos anos 2000, contemplando que países africanos e asiáticos absorverão os impactos futuros dessa rápida mudança no uso da terra.

Na América do Sul, o Brasil se destaca pela extensão do seu território e o contingente populacional que abriga. Segundo Confalonieri (2008), a região nordeste deve ser prioridade quanto o assunto é vulnerabilidade socioambiental brasileira, dado um conjunto de fatores (relacionados a questão da seca, processos migratórios e falta de investimento governamental na região, por exemplo) o que torna essa zona mais favorável a sofrer com os impactos do clima, no que se refere ao setor de saúde.

No Brasil, Barcellos et al. (2009) também exalta a região amazônica como sendo mais vulnerável às mudanças climáticas em razão dos processos antrópicos (queimadas e desmatamento), que alteram o uso do solo e interferem na dinâmica do bioma.

Espera-se, diante do exposto, que os efeitos na saúde decorrentes dessas mudanças aumentem a carga de doenças nessas e em outras regiões do globo e exacerbem a carga existente em sistemas de saúde, já frágeis, pelo aumento da taxa de mortalidade e morbidade (BARCELLOS et al., 2009; BERRANG-FORD et al., 2012). Desse modo, é preciso compreender que os impactos climáticos geram custos econômicos e exigem medidas de mitigação e de adaptação social (WHO, 2018).

Cabe salientar que a atual pandemia de SARS-CoV2 exemplifica bem como os efeitos locais do surgimento de uma doença infecciosa ocasionada por diversos fatores (sociais, ambientais e climáticos), pode provocar em escala global e em diferentes segmentos sociais, demonstrando assim, a importância de medidas de mitigação e adaptação.

Assim, as medidas de adaptação ao clima devem ser promovidas conjuntamente com mudanças nas políticas que visem a diminuição da pressão sobre os recursos, atenuem os riscos ambientais e aumentem a capacidade de adaptação (WHO, 2018), reduzindo consequentemente, os impactos econômicos e à saúde, oriundos das alterações ambientais e climáticas em diversos países, em especial, naqueles mais vulneráveis (JANKOWSKA et al., 2012).

De acordo com Ojima e Marandola Jr (2010), indicadores de adaptação e vulnerabilidade são uma necessidade na gestão pública, pois auxiliam na identificação de áreas e grupos mais vulneráveis, uma vez que a vulnerabilidade deve compreender "a heterogeneidade inerente aos indivíduos, grupos familiares, bairros, cidades e regiões".

Assim, espera-se que estratégias sejam aplicadas intensamente nos locais designados como mais vulneráveis para auxiliar o desenvolvimento local e 
diminuir impactos globais futuros oriundos de novas doenças, e que medidas de adaptação sejam elaboradas corretamente a partir de indicadores bem desenhados (CONFALONIERI et al., 2015; JANKOWSKA et al., 2012).

\section{CONSIDERAÇÕES FINAIS}

Esta pesquisa objetivou compreender a relação entre o surgimento de doenças infecciosas, consideradas como epidêmicas e pandêmicas pela WHO (2020), com as mudanças climáticas, abordando, ainda, a questão da vulnerabilidade socioambiental, a partir de uma revisão integrativa do tema.

Nesse contexto, o trabalho evidenciou que as doenças aqui descritas são, direta ou indiretamente, influenciadas por fatores climáticos e ambientais, sendo potencializadas, também, por questões sociais. Além disso, todas as doenças infecciosas mencionadas tiveram origem e relatos de casos em humanos, no continente africano ou asiático, o que corresponde aos dados de que esses continentes representam as regiões mais vulneráveis do globo.

Assim, conhecendo-se os locais mais vulneráveis, os fatores que corroboram para o agravamento da vulnerabilidade $e$ as possíveis consequências e efeitos das mudanças climáticas sobre essas regiões, é possível criar medidas de mitigação e adaptação que promovam o desenvolvimento social e ambiental dessas populações. Concomitantemente, é possível evitar com que doenças infecciosas surjam, disseminem-se e provoquem danos em escala mundial, perpassando por distintos setores (saúde, economia, educação, entre outros) e exacerbando problemas já existentes neles.

Diante do exposto, este trabalho contribuiu ao campo de pesquisa referente à saúde e mudanças climáticas, ao sinalizar condições ambientais, climáticas e sociais, que são cruciais para o entendimento das doenças infecciosas e das causas associadas ao surgimento delas, bem como por demonstrar como tais condições estão relacionadas à vulnerabilidade socioambiental e como esta é mais acentuada em determinadas regiões, que carecem de ações de mitigação e adaptação.

\section{REFERÊNCIAS}

ADAMS, C.; IDE, T.; BARNETT, J.; DETGES, A. Sampling bias in climate-conflict research. Nature Climate Change, vol. 8, p. 200-203, 2018.

ADGER, W.N.; EAKIN, H.; WINKELS, A. Nested and teleconnected vulnerabilities to environmental change. Frontiers in Ecology and the Environment, v.7, n.3, p.150-157, 2008.

AHMADI, M.; SHARIFI, A.; DOROSTI, S.; GHOUSHCHI, S.J.; GHANBARI, N. Investigation of effective climatology parameters on COVID-19 outbreak in Iran. Science of the Total Environmental, v.729, 2020.

AKHOUNDI, M.; KUHLS, K.; CANNET, A.; VOTYPKA, J.; MARTY, P.; DELAUNAY, P.; SERENO, D. A Historical Overview of the Classification, Evolution, and Dispersion of Leishmania Parasites and Sandflies. PLOS Neglected Tropical Diseases, v.10, n.3, 2016. 
ALHO, C.J.R. Importância da biodiversidade para a saúde humana: uma perspectiva ecológica. Estudos Avançados, v. 26, n. 74, p. 151-166, 2012.

ALI, H.; DUMBUYA, B.; HYNIE, M.; IDAHOSA, P.; KEIL, R.; PERKINS, P. The Social and Political Dimensions of the Ebola Response: Global Inequality, Climate Change, and Infectious Disease, In: Leal Filho, W., Azeiteiro, U., Alves, F. (Eds.), Climate Change and Health: Improving Resilience and Reducing Risks. Springer International Publishing, Switzerland, p.151-170, 2016.

ALI, M.; NELSON, A.R.; LOPEZ, A.L.; SACK, D.A. Updated global burden of cholera in endemic countries. Plos Neglected Tropical Diseases. 2015.

AZMAN, A.S.; LUQUERO, F.J.; RODRIGUES, A.; PALMA, P.P.; GRAIS, R.F.; BANGA, C.N. Urban cholera transmission hotspots and their implications for reactive vaccination: evidence from Bissau city, Guinea bissau. PLoS Neglected Tropical Diseases, v.6, n.11, 2012.

BALBUS, J.; CRIMMINS, A.; GAMBLE, J.L.; EASTERLING, D.R.; KUNKEL, K.E.; SAHA, S.; SAROFIM, M.C. Climate Change and Human Health. In: The Impacts of Climate Change on Human Health in the United States: A Scientific Assessment. Washington, DC: U.S. Global Change Research Program, (p.2542), 2016.

BARCELlOS, C.; MONTEIRO, A.M.V.; CORVALÁN, C.; GURGEL, H.C.; CARVALHO, M.S.; ARTAXO, P.; HACON, S.; RAGONI, V. Mudanças climáticas e ambientais e as doenças infecciosas: cenários e incertezas para o Brasil. Revista Epidemiologia e Serviços de Saúde, Brasília, v.18, n.3, p.285-304, 2009.

BARCELLOS, C.; ROUX, E.; CECCATO, P.; GOSSELIN, P.; MONTEIRO, A.M.; MATO, V.P.; XAVIER, D.R. An observatory to gather and disseminate information on the health-related effects of environmental and climate change. Revista Panamericana de Salud Pública, v.40, n.3, 2016.

BELL, D.; ROBERTSON, S.; HUNTER, P.R. Animal origins of SARS coronavirus: possible links with the international trade in small carnivores. Philosophical Transaction of the Royal Society B, v.359, p.1107-14, 2004.

BERRANG-FORD, L.; DINGLE, K.; FORD, J.D.; LEE, C.; LWASA, S.; NAMANYA, D.B.; HEDERSON, J.; LLANOS, A.; CARCAMO, C.; EDGE, V. Vulnerability of indigenous health to climate change: A case study of Uganda's Batwa Pygmies. Social Science \& Medicine, v.75, p.1067-1077, 2012.

BRAACK, L.; ALMEIDA, A.P.G.; CORNEL, A.J.; SWANEPOEL, R.; JAGER, C. Mosquito-borne arboviruses of American origin: review of key viruses and vectors. Parasites \& Vectors. 2018.

BONNE, C. Sons of the Soil Conflict in Africa: Institutional Determinants of Ethnic Conflict Over Land. World Development, v.96, p. 276-293, 2017.

BOUMA, M.J.; VAN DER KAAY, H.J. Epidemic malaria in India and the El Niño southern oscillation. Lancet, v.344, p.1638-1639, 1994.

CAUCHEMEZ, S.; NOUVELlET, P.; CORI, A.; JOMBART, T.; GARSKE, T.; CLAPHAM, H.; MOORE, S.; MILLS, H.L.; SALJE, H.; COLLINS, C.; RODRIQUEZBARRAQUER, I.; RILEY, S.; TRUELOVE, S.; ALGARNI, H.; ALHAKEEM, R.; ALHARBI, K.; TURKISTANI, A.; AGUAS, R.J.; CUMMINGS, D.A.T.; KERKHOVE, M.D.V.; DONNELLY, C.A.; LESSLER, J.; FRASER, C.; AL-BARRAK, A.; 
FERGUSON, N.M. Unraveling the drivers of MERS-COV transmission. Proceedings of the National Academy of Sciences of the United States of America, v.113, n.32, p.9081-9086, 2016.

CHAKRABORTY, I.; MAITY, P. COVID-19 outbreak: Mitigation, effects on society, global environment and prevention. Science of the Total Environment. 2020.

CHRETIEN, J.P.; ANYAMBA, A.; SMALL, J.; BRITCH, S.; SANCHEZ, J.L.; HALBACH, A.C.; LINTHICUM, K.J. Global climate anomalies and potential infectious disease risks: 2014-2015. PLoS Currents, v.26, n.7. 2015.

COWELL, R.R. Global climate and infectious disease: the cholera paradigm. Science, v.274, n.5295, p.2025-2031, 1996.

CONFALONIERI, U.E.C. Mudança climática global e saúde humana no Brasil. Parcerias Estratégicas. Brasília, v.27, 2008.

CONFALONIERI, U.E.C.; MENEZES, J.A.; SOUZA, C.M. Climate change and adaptation of the health sector: The case of infectious diseases. Virulence, v.6, n.6, p.554-557, 2015.

COSTA, J.M.L. Epidemiologia das Leishmanioses no Brasil. Gazeta Médica da Bahia, Salvador, v.1, p.3-17, 2005.

DOGRA, N.; KAKDE, V.; TANEJA, P. Decision tool for climate disasters and infectious disease at sub-national level in India: Ensuring a paradigm shift in health planning from prevalence to vulnerability. Acta Tropica, v.191, p.60-68, 2019.

EBI, K.L.; BALBUS, J.M.; LUBER, G.; BOLE, A.; CRIMMINS, A.; GLASS, G. Human Health. In D. R. Reidmiller, D. R., Avery, C. W., Easterling, D. R., Kunkel, K. E., Lewis, K. L. M., Maycock, T. K., \& Stewart, B. C. (Eds.), Impacts, Risks, and Adaptation in the United States: Fourth National Climate Assessment, Global Change Research Program, v.2, p. 539-571, 2018.

EBI, K.L.; HESS, J.J. The past and future in undestanding the health risks of and responses to climate variability and change. International Journal of Biometeorology, v.61, p.71-80, 2017.

ERIKSEN, S.; SELBOE, E. The social organisation of adaptation to climate variability and global change: The case of a mountain farming community in Norway. Applied Geography, v.33, p.159-167, 2012.

FAO. Food and Agriculture Organization of the United Nations. Human Exposure to Middle East Respiratory Syndrome Coronavirus from Livestock or Wildlife Species (August 2017). FAO Animal Health Risk Analysis - Assessment, n. 4, 2017.

FEKADU, G.; AYELET, G.; ABUNNA, F. Epodemiological investigation of Middle East respiratory syndrome corona virus (mers-cov) among dromedary camels in selected areas of Afar and Oromia region, Ethiopia. Journal of Veterinary Medicine and Animal Health, v.9, n.3, p.47-54, 2016.

FIERROS-HERNÁNDEZ, A.; AYALA-ZÚÑIGA, A. Epidemics which never came: yellow fever (1883) and bubonic plague (1902-1903) in Baja California. Gaceta Médica de México, 2016. 
FLATO, M.; MUTTARAK, R.; PELSER, A. Women, Weather, and Woes: The Triangular Dynamics of Female-Headed Households, Economic Vulnerability, and Climate Variability in South Africa. World Development, v.90, p.41-62, 2017.

GAGE, K.L.; BURKOT, T.R.; EISEN, R.J; HAYES, E.B. Climate and vectorborne diseases. American Journal of Preventive Medicine, v.35, n.5, p.436-450, 2008.

GORRIS, M.E. Environmental infectious disease dynamics in relation to climate and climate change, University of California, Irvine (Dissertation). 170p, 2019.

GOULET, C. A multi-scale evaluation of eastern hognose snake (Heteridin platirhinos) habitat selection at the northern extent of its range. University of News Hampshire. Master's Theses and Capstones. 109p, 2010.

GUBLER, D.J.; REITER, P.; EBI, K.L.; YAP, W.; NASCI, R.; PATZ, J.A. Climate variability and change in the United States: potential impacts on vector-and rodent-borne diseases. Environmental Health Perspectives, v.109, p.223-233, 2001.

GUIMARÃES, R.B.; CATÃO, R.C.; CASAGRANDE, B. Raciocínio geográfico e complexos patogênicos atuais: análise comparativa da Dengue e da Leishmaniose Tegumentar Americana. Revista franco-brasileira de geografia, v.37, 2018.

GUTIÉRREZ, M.E.; ESPINOSA, T. Vulnerabilidad y adaptación al cambio climático-Diagnóstico inicial, avances, vacíos y potenciales líneas de acción en Mesoaémrica. BID Banco Interamericano de Desarrollo. Notas Técnicas. 2010.

HAILU A.; DAGNE D.A.; BOELAERT, M. Leishmaniasis. In: GYAPONG, J.; BOATIN, B. (eds) Neglected Tropical Diseases - Sub-Saharan Africa, Springer, p. 87-112, 2016.

HARB, M.; FARIS, R.; GAD, A.M.; HAFEZ, O.N.; RAMZY, R.; BUCK, A.A. The resurgence of lymphatic filariasis in the Nile delta. Bulletin of the World Health Organization, v.71, n.1, p.49-54, 1993.

HASEN, J.; SATO, M. Regional climate change and national responsibilities. Environmental Research Letters, v.11, n.3, 2016.

HAWASS, Z.; GAD, Y.Z.; ISMAIL, S.; KHAIRAT, R.; FATHALLA, D.; HASAN, N.; AHMED, A.; EELEITHY, H.; BALL, M.; GABALLAH, F.; WASEF, S.; FATEEN, M.; AMER, H.; GOSTNER, P.; SELIM, A.; ZINK, A.; PUSCH, C.M. Ancestry and Pathology in King Tutankhamun's Family. Journal of American Medical Association, v.303, n.7, 2010.

HORWOOD, P.F.; GREENHILL, A.R. Cholera in Oceania. In: Loukas A. editor. Neglected Tropical Diseases of Oceania. Basel: Springer International Publishing, p. 1-31, 2016.

HUANG, F., ZHOU, S., ZHANG, S., WANG, H., TANG, L. Temporal correlation analysis between malaria and meteorological factors in Motuo County, Tibet. Malar. J, v. 10, n.1, 54p, 2011.

IPCC. Intergovernmental Panel on Climate Change. Climate Change 2001: Third Assessment Report (Volume II), Impacts, Vulnerability and Adaptation. Cambridge: Cambridge University Press, 2001. 
IPCC. Intergovernmental Panel on Climate Change. Summary for Policymakers. In: Climate Change 2014: Mitigation of Climate Change, 2014.

JANKOWSKA, M.M.; LOPEZ-CARR, D.; FUNK, C.; HUSAK, G.J.; CAFE, Z.A. Climate change and human health: Spatial modeling of water availability, malnutrition, and livelihoods in Mali, Africa. Applied Geography, v.33, p.4-15, 2012.

JOLY, C.A. Biodiversidade e Mudanças Climáticas: Contexto Evolutivo, Histórico e Político. Ambiente e Sociedade, Campinas, v.X, n.1, p-162-172, 2007.

KILPATRICK, A.M.; MEOLA, M.A.; MOUNDY, R.M.; KRAMER, L.D. Temperature, viral genetics, and the transmission of West Nile virus by Culex pipiens mosquitoes. PLoS Pathogens, 2008.

LACKLAND, D.T. Systemic Hypertension: An endemic, epidemic, and a Pandemic. Seminars in Nephrology, v.25, p.194-197, 2005.

LIANG, X.; AGGARWAL, R.; CHERIF, A.; GUMEL, A.; MASCARO, G.; MACIEJEWSKI, R. Visualizing Malaria spread under climate change. Workshop on Visualisation in Environmental Sciences, 5p, 2016.

LIU, J.; ZHOU, J.; YAO, J.; ZHANG, X.; LI, L.; XU, X.; HE, X.; WANG, B.; FU, S.; NIU, T.; YAN, J.; SHI, Y.; REN, X.; NIU, J.; ZHU, W.; LI, S.; LUO, B.; ZHANG, K. Impact of meteorological factors on the COVID-19 transmission: A multi-city study in China. Science of the Total Environmental, v. 726, 2020.

MENDONÇA, F. Riscos e vulnerabilidades socioambientais urbanos a contingência climática. Mercator-Revista de Geografia da UFC, v.9, n.1, p.153163, 2010.

METCALF, C.J.E.; WALTER, K.S.; WESOLOWSKI, A.; BUCKEE, C.O.; SHEVLIAKOVA, E.; TATEM, A.J.; BOOS, W.R.; WEINBERGER, D.M.; PITZER, V.E. Identifying climate drivers of infectious disease dynamics: recent advances and challenges ahead. The Royal Society, 2017.

NEEDHAM, G.R.; TEEL, P.D. Off-host physiological ecology of ixodid ticks. Annual Review of Entomology, v.36, n.1, p.659-681, 1991.

NGUYEN, K.; LIOU, Y. Global mapping of eco-environmental vulnerability from human and nature disturbances. Science of the Total Environment, v.664, p.995-1004, 2019.

NORDSQVIST, P.; KRAMPE, F. Climate Change and Violent Conflict: Sparse Evidence from South Asia and South East Asia. Stockholm International Peace Research Institute, $2018 . \quad$ Disponível: https://www.jstor.org/stable/resrep24462?seq=1\#metadata_info_tab_contents Acessado: 04/03/2021.

NUNES, M.L.; OLIVEIRA, S.V.; ELKHOURY, M, R.; FONSECA, L.X.; PEREIRA, S.V.C.; CALDAS, E.P.; GUIMARÃES, J.C.N.; ROSA, E.S.T.; BONVICINO, C.R.; DÁNDREA, P.S. Evidências de circulação de hantavírus em área silenciosa da Região Amazônica. Revista Pan-Amazônica de Saúde, v.6, n.4, 2015.

OJIMA, R.; HOGAN, D.J. População, urbanização e ambiente no cenário das mudanças ambientais globais: debates e desafios para a demografia brasileira. In: XVI Encontro Nacional de Estudos Populacionais, Caxambu. Anais... Caxambu: ABEP, 2008a. 
OJIMA, R.; HOGAN, D.J. Crescimento urbano e mudança climática: pontos de convergência nos limites da urbanização contemporânea. In: III Congresso da Associação Latino Americana de População, ALAP, Córdoba, 2008b.

OJIMA, R.; MARANDOLA, JR. E. Indicadores e políticas públicas de adaptação às mudanças climáticas: vulnerabilidade, população e urbanização. Revista Brasileira de Ciências Ambientais, n.18, 2010.

O'REILLY, K.M.; AUZENBERGS, M.; JAFARI, Y.; LIU, Y.; FLASCHE, S.; LOWE, R. Effective transmission across the globe: the role of climate in COVID-19 mitigation strategies. Lancet Planet Health, v.4, n.5, 2020.

PATZ, J.A.; GITHEKO, A.K.; MCCARTY, J.P.; HUSSEIN, S.; CONFALONIERI, U.; de WET, N. Climate Change and infections diseases. In: MCMICHAEL, A.; CAMPBELL-LENDRUM, D.; CORVALA'N, C.; EBI, K.; GITHEKO, A.; SCHERAGA, J.; WOODWARD, A. (Eds.), Climate Change and Human Health: Risks and Response. World Health Organization, Geneva, p.103-132, 2003.

PATZ, J.A.; MCGEEHIN, M.A.; BERNARD, S.M.; EBI, K.L.; EPSTEIN, P.R.; GRAMBSCH, A.; GUBLER, D.J.; ROMIEU, I.; ROSE, J.B.; SAMET, J.M.; TRTANJ, J. The potential health impacts of climate variability and change for the United States: executive summary of the report of the health sector of the U.S. National Assessment. Environmental Health Perspectives, v.108, p.367-76, 2000.

PITELKA, L.F.; GROUP, P.M.W. Plant migration and climate change. American Scientist, v.85, p. 464-473, 1997.

QAYYUM, U.; ANJUM, S.; SABIR, S. Armed Conflicts, Militarisation and Ecological Footprints: Empirical Evidence from South Asia, Journal of Cleaner Production, v.281, 2021.

RASTOGI, Y.R.; SHARMA, A.; NAGRAIK, R.; AYGÜN, A.; SEN, F. The novel coronavirus 2019-nCov: Its evolution and transmission into humans causing global COVID-19 pandemic. International Journal of Environmental Science and Technology, 8p, 2020.

REPERANT, L.A.; OSTERHAUS, A.D.M.E. AIDS, Avian flu, SARS, MERS, Ebola, Zika... what next? Vaccine, v.35, p.4470-4474, 2017.

SALVADOR, C.; NIETO, R.; LINARES, C.; DÍAZ, J.; GIMENO, L. Effects of droughts on health: Diagnosis, repercussion, and adaptation in vulnerable regions under climate change, Challenges for future research. Science of the Total Environmental, v.703, 2020.

SANTOS, J.P.; STEINKE, V.A.; OLIVEIRA, S.V.; GARCÍA-ZAPATA, M.T.A. Espaço e doença: mudanças antrópicas e a hantavirose. Revista Brasileira de Geografia Médica e da Saúde, v.12, n.22, p.1-12, 2016.

SMITH, E. The effect of potential climate change on infectious disease presentation. The Journal for Nurse Practitioners, n.15, p-405-409, 2019.

SMITH, K.R.; WOODWAR, A.; CAMPBELL-LENDRUM, D.; CHADEE, D.D.; HONDA, Y.; LIU, Q.; OLWOCH, J.; REVICH, B.; SAUERBORN, R.; ARANDA, C.; BERRY, H.; BUTLER, C. Human health: impacts, adaptation, and co-benefits. In: C. B. FIELD, V. BARROS, D.J. DOKKEN (Eds.), Climate Change 2014: Impacts, Adaptation, and Vulnerability. Part A: Global and Sectoral Aspects. Contribution 
of Working Group II to the Fifth Assessment Report of the Intergovernmental Panel on Climate Change (p. 709-754). Cambridge, United Kingdom and New York, NY, USA: Cambridge University Press, 2014.

SOUZA, M.T.; SILVA, M.D.da.; CARVALHO, R. Revisão integrativa: o que é e como fazer. Einstein, v.8, n.1, 2010.

TAYLOR, L.H.; LATHAM, S.M.; WOOLHOUSE, M.E.J. Risk factors for human disease emergence. Philosophical Transactions of the Royal Society B, v.356, p.983-989, 2001.

UCHOA, N.M.; LUSTOSA, R.P.; UCHOA, F.N.M. Relação entre mudanças climáticas e saúde humana. Revinter, v.12, n.1, p.11-118, 2019.

VASCONCELOS, P.F.C. Febre Amarela. Revista da Sociedade Brasileira de Medicina Tropical, v.36, n.2, p.275-293, 2003.

VOLK, S.M.; CHEN, R.; TSETSARKIN, K.A.; ADAMS, A.P.; GARCIA, T.I.; SALL, A.A.; NASAR, F.; SCHUH, A.J.; HOLMES, E.C.; HIGGS, S.; MAHARAJ, P.D.; BRAULT, A.C.; WEAVER, S.C. Genome-scale phylogenetic analyses of chikungunya virus reveal independent emergences of recent epidemics and various evolutionary rates. Journal of Virology, v.84, p.6497-6504, 2010.

WHO. World Health Organization. Climate Change and Health. 2018. Disponível em: <https://www.who.int/news-room/fact-sheets/detail/climate-change-andhealth>Acessado em junho de 2020.

WHO. World Health Organization. Emergences-Diseases Outbreakes. 2020. Disponível em: < https://www.who.int/emergencies/diseases/en/>Acessado em junho de 2020.

WILSON, M.L. Ecology and infectious disease. In: Ecosystem change and public health: a global perspective, ARON J.L.; PATZ, J.A. (eds). Baltimore, USA, John Hopkins University Press, p. 283-324, 2001.

WU, Y.; QIAO, Z.; WANG, N.; YU, H.; FENG, Z.; LI, X.; ZHAZO, X. Describing interaction effect between lagged rainfalls on malaria: an epidemiological study in south-west China. Malaria Journal, v.16, n.53, 2017.

XIANG, J.; HANSEN, A.; LIU, Q.; LIU, X.; TONG, M.X.; SUN, Y.; CAMERON, S.; HANSON-EASEY, S.; HAN, G.S.; WILLIAMS, C. Association between dengue fever incidence and meteorological factors in Guangzhou, China, 2005-2014. Environmental Research. v.153, p.17-26, 2017.

XIANG, J.; HANSEN, A.; LIU, Q.; TONG, M.X.; LIU, X.; SUN, Y.; CAMERON, S. ; HANSON-EASEY, S.; HAN, G.S.; WILLIAMS, C.; WEINSTEIN, P.; BI, P. Association between malaria incidence and meteorological factors: a multi location study in China, 2005-2012. Epidemiology \& Infection. v.146, n.1, p.8999, 2018.

YI, L.; XU, X.; GE, W.; XUE, H.; LI, J.; W, C.; WU, H.; LIU, X.; ZHENG, D.; CHEN, Z.; LIU, Q.; BI, P.; LI, J. The impact of climate variability on infectious disease transmission in China: Current knowledge and further directions. Environmental Research, v. 173, p.255-261, 2019 